\title{
Flow intake control using dry-weather forecast
}

\author{
Otto Icke $^{1}$, Kim van Schagen ${ }^{1}$, Christian Huising ${ }^{2}$, Jasper Wuister ${ }^{1}$, Edward van Dijk $^{1}$, and \\ Arjan Budding ${ }^{2}$ \\ ${ }^{1}$ Business Unit Water, Royal HaskoningDHV, Amersfoort, 3800 BC, the Netherlands \\ ${ }^{2}$ Policy Department, Water authority Vallei en Veluwe, Apeldoorn, 7320 AC, the Netherlands
}

Correspondence to: Otto Icke (otto.icke@ rhdhv.com)

Received: 23 January 2017 - Discussion started: 3 February 2017

Revised: 26 June 2017 - Accepted: 3 July 2017 - Published: 15 August 2017

\begin{abstract}
Level-based control of the influent flow causes peak discharges at a waste water treatment plant (WWTP) after rainfall events. Furthermore, the capacity of the post-treatment is in general smaller than the maximum hydraulic capacity of the WWTP. This results in a significant bypass of the post-treatment during peak discharge. The optimisation of influent flow reduces peak discharge, and increases the treatment efficiency of the whole water cycle, which benefits the surface water quality. In this paper, it is shown that half of the bypasses of the post-treatment can be prevented by predictive control. A predictive controller for influent flow is implemented using the Aquasuite ${ }^{\circledR}$ Advanced Monitoring and Control platform. Based on real-time measured water levels in the sewerage and both rainfall and dry-weather flow (DWF) predictions, a discharge limitation is determined by a volume optimisation technique. For the analysed period (February-September 2016) results at WWTP Bennekom show that about $50 \%$ of bypass volume can be prevented. Analysis of single rainfall events shows that the used approach is still conservative and that the bypass can be even further decreased by allowing discharge limitation during precipitation.
\end{abstract}

\section{Introduction}

The influent flow to most waste water treatment plants (WWTPs) is currently controlled by only the level in the sewerage. This level-based control of the influent flow causes peak discharges at a WWTP after rainfall events, even if there is enough storage available in the sewerage to discharge the precipitation in a more gradual way. As a result both hydraulic and biological peak loads are considerable. This affects the performance of the WWTP. Furthermore, the capacity of the post-treatment is in general smaller than the maximum hydraulic capacity of the WWTP. This results in a significant bypass of the post-treatment during peak discharge.

Therefore, reduction of peak discharge by optimising the influent flow control is expected to be effective. Predictive control with dry-weather forecast can be applied to limit the influent flow at the end of (or even during) rainfall events. Where level-based control is characterised by a reactive response, predictive control anticipates changing circumstances. In this way the available storage of the sewerage can be used without causing extra combined sewer overflow (CSO) or water on street (WOS). This increases the treatment efficiency of the whole water cycle, which benefits the surface water quality.

For WWTP Woudenberg preliminary study was carried out on using predictive control. It was shown that the amount of bypass can be reduced by approximately $65 \%$ (van Dijk, 2013). The study used a conservative approach, in which the discharge is limited after the rainfall event. It was suggested that the amount of bypass could be even more reduced in case the discharge is limited during the rainfall event. However, this could lead to more CSO or WOS if amounts of rainfall are predicted incorrectly. To verify the results of the preliminary study, a pilot project was started for four catchment areas, to investigate the true reduction of bypass using predictive control. This paper describes the methodology, implementation and results of one of the four pilots illustrating the effectiveness of predictive control in reducing peak discharges to the WWTP. 


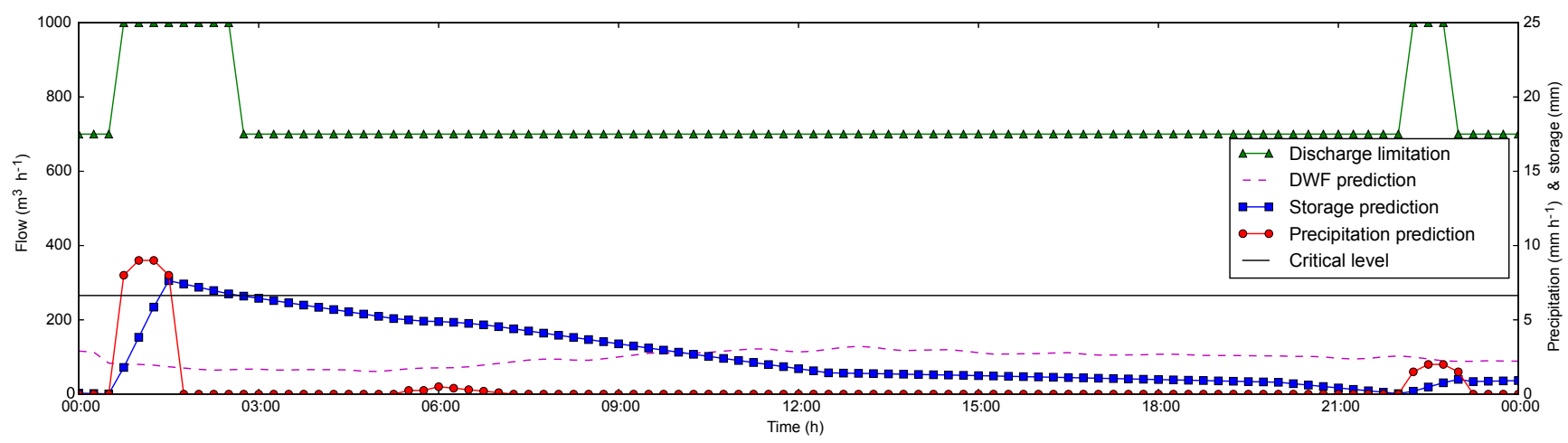

Figure 1. Outline of the predictive control for the influent flow of WWTP Bennekom (Icke et al., 2016).

\section{Material and methods}

A predictive controller for influent flow is implemented in this pilot project using the Aquasuite ${ }^{\circledR}$ Advanced Monitoring and Control platform (van der Kolk, 2016). The controller is used to limit the flow at pumping stations discharging from the sewerage to the WWTP. Rainfall and dry-weather flow (DWF) predictions are applied as the basis for the predictive control.

The rainfall prediction is obtained from the High Resolution Limited Area Model (HIRLAM) of the Royal Netherlands Meteorological Institute (KNMI). The DWF prediction is obtained by a measurement data driven technique (Bakker et al., 2013a). Based on real-time measured water levels in the sewerage and both rainfall and DWF predictions, a discharge limitation is determined by a volume optimisation technique (Bakker et al., 2013b). This is shown in Fig. 1.

During a rainfall event, the discharge limitation is at maximum capacity. After the rainfall event, when levels are below a defined critical level, the sewerage is emptied with a limited discharge. In Fig. 1 an example with a discharge limitation at $70 \%$ of the maximum capacity is shown. Based on the time until the next rainfall event and the maximum time to empty the sewerage, the influent flow is optimised between the maximum capacity and the capacity of the post-treatment.

\subsection{Rainfall forecast}

As travelling times of the sewerage can take up to $24 \mathrm{~h}$ (RIONED, 2008), precipitation predictions with similar periods are required. Optimal utilisation of the storage of the sewerage is only possible with information of subsequent rainfall peaks. Therefore, at the beginning of this project, HIRLAM of the KNMI was selected as the numerical weather prediction (NWP) forecast system from which the precipitation data were obtained. This rainfall forecast has raster cell sizes of 11.0 by $7.0 \mathrm{~km}$, a forecast horizon of $48 \mathrm{~h}$ and a refresh rate of circa $6 \mathrm{~h}$. A single time series is obtained for each specified area by transforming the information of the raster cells within the polygon by application of a geostatistical method.

\subsection{Dry-weather flow prediction}

An accurate prediction of the dry-weather flow is essential to determine the total predicted flow to the WWTP. The influent flow has, at WWTPs with mainly domestic waste water, a typical day pattern. Both (time-dependent) water demand of inhabitants and contribution of industrial discharges, as well as properties of the sewerage like travelling time, influence the exact characteristics of this pattern.

A data driven technique is applied to obtain this DWF prediction which is self-learning based on real-time flow measurements. Based on previously occurring patterns of each specific day of the week, a daily curve is automatically obtained, except for those with deviations due to peak flows caused by precipitation. Combination of the prediction of the total daily volume with this predicted curve determines a DWF prediction. For each specific catchment area, a distinct DWF prediction is obtained. The DWF prediction has a $48 \mathrm{~h}$ forecast horizon, just like the rainfall forecast.

This particular technique is based on the fully adaptive forecasting model for short-term drinking water demand (Bakker et al., 2013a). It is so generic that it can be applied to waste water discharge with some small adjustments of the settings. Before this pilot project, the application of this technique to waste water discharge had already successfully been implemented, yet with a rather different objective. DWF prediction is an accurate measure for the load of biological oxygen demand (BOD) prediction. Therefore, it can be applied within a predictive controller for aeration (de Koning et al., 2013).

\subsection{Predictive control}

A volume optimisation technique is applied to determine predicted storage and discharge. This technique is in principle equal to the predictive control applied in drinking water supply (Bakker et al., 2013b). For that specific purpose, the outflow of a reservoir is determined by the water demand prediction of the supply area, and the inflow of the reservoir is kept as constant as possible within the constraints. In this pi- 
lot project, this technique is applied to reduce peak flow to the WWTP after rainfall using the available storage of the sewer. The outflow of the reservoir is kept limited within the constraints.

The predictive controller for influent flow control as implemented for this pilot project consists of the following components. Firstly, actual utilised storage of the sewerage is derived from real-time water level measurements and relationships between level and volume. These relationships are obtained from storage curves derived from sewer models and are verified with measured values for level and discharge. Subsequently, the inflow to the sewerage is predicted. The sum of runoff, DWF and discharge predictions of connected upstream catchments determines the inflow prediction. The runoff is based on the connected paved area and the precipitation prediction. In the third step, the sewerage is modelled as a single reservoir for each catchment, which is optimally used within the imposed constraints. This results in the optimal outflow prediction.

Only if the actual level in the sewerage is lower than a critical level and the predicted precipitation is below a threshold, is discharge limitation turned on. The discharge is limited to an optimal capacity meeting the imposed constraints. In case a subsequent significant rainfall event is forecasted at a moment before the sewerage can be completely emptied at posttreatment capacity, discharge will be optimised. Depending on the local configuration, the discharge can either be gradually limited between maximum and post-treatment capacity or kept at maximum capacity for a calculated period after the rainfall event. In this way, the sewerage is emptied before the next rainfall event, and bypass of the post-treatment is minimised.

\subsection{Implementation}

For the pilot project this control is implemented for the WWTPs Bennekom, Ede, Woudenberg and Harderwijk (Netherlands). These are conventional WWTPs with a posttreatment. The allocated hydraulic capacity of the posttreatment is for all these locations lower than the hydraulic capacity of the WWTP. The implementation is executed in close cooperation between water authority Vallei and Veluwe and the connected municipalities. The predictive controller is implemented for all four locations. This study analyses the implementation of WWTP Bennekom in detail.

Before implementation, influent flow at WWTP Bennekom took place at three different stages: 200, 500 and $1000 \mathrm{~m}^{3} \mathrm{~h}^{-1}$. Only switching between fixed stages is possible, since none of the screw pumps are provided with variable speed drives. However, above $700 \mathrm{~m}^{3} \mathrm{~h}^{-1}$ silting of the sand filters occurs. Therefore, an extra fixed stage of $700 \mathrm{~m}^{3} \mathrm{~h}^{-1}$ was configured for this project. In case of suitable conditions discharge is limited from 1000 to $700 \mathrm{~m}^{3} \mathrm{~h}^{-1}$ by the predictive control.

\subsection{Phasing and monitoring}

The predictive control was first implemented in advisory mode to check the results in the real-time, full-scale situation. After this period the control is switched on if the results from the advisory period were satisfactory. The control is continuously monitored by the application of key performance indicators (KPIs) for both sewerage and post-treatment. Storage utilisation and travelling time were defined as the main KPIs for the sewerage. The efficiency of the predictive control itself was defined as a major KPI for the post-treatment. The efficiency of the predictive control is determined as the ratio of the bypass of the post-treatment prevented and the amount of bypass for the situation without predictive control (Icke et al., 2016).

\section{Results and discussion}

In advisory mode the results prove that most of the rainfall events could have been discharged to the WWTP with a reduced capacity and therefore the amount of bypass can be reduced without extra CSO. At the beginning of February 2016 the predictive control for WWTP Bennekom was activated. The predictive control has been continuously activated, apart from the period between 10 and 12 February and 13 and 14 March due to maintenance activities. During the analysed period (February-September) several precipitation events which could cause bypass occurred.

\subsection{Performance control total period}

The performance of the predictive control at WWTP Bennekom for the analysed period is shown in Fig. 2. Both the amount of bypass that occurred and the amount that was prevented are presented for each day. For those days where the predictive control was (partially) deactivated due to maintenance activities, the prevented bypass was predicted.

For the analysed period (February-September 2016) the results at WWTP Bennekom show that $51 \%$ of bypass volume has been prevented with predictive control compared to the original situation with level-based control. The results also show that big differences occur between the months regarding the effect of the predictive control. The analysed period covers two-thirds of the year, including the whole summer period.

During the first 3 months (February-April) $67 \%$ of the bypass could have been prevented by predictive control; however, this was in reality $12 \%$ lower due to maintenance activities. The effects of subsequent rainfall events were limited, since the intervals between distinct predicted events were in general longer than the travelling time with reduced capacity (Icke et al., 2016). Maximum travelling times did not exceed $12 \mathrm{~h}$ and the reduction of bypass occurred without extra CSO. The precipitation during this (early) spring period can be characterised as gradual. 


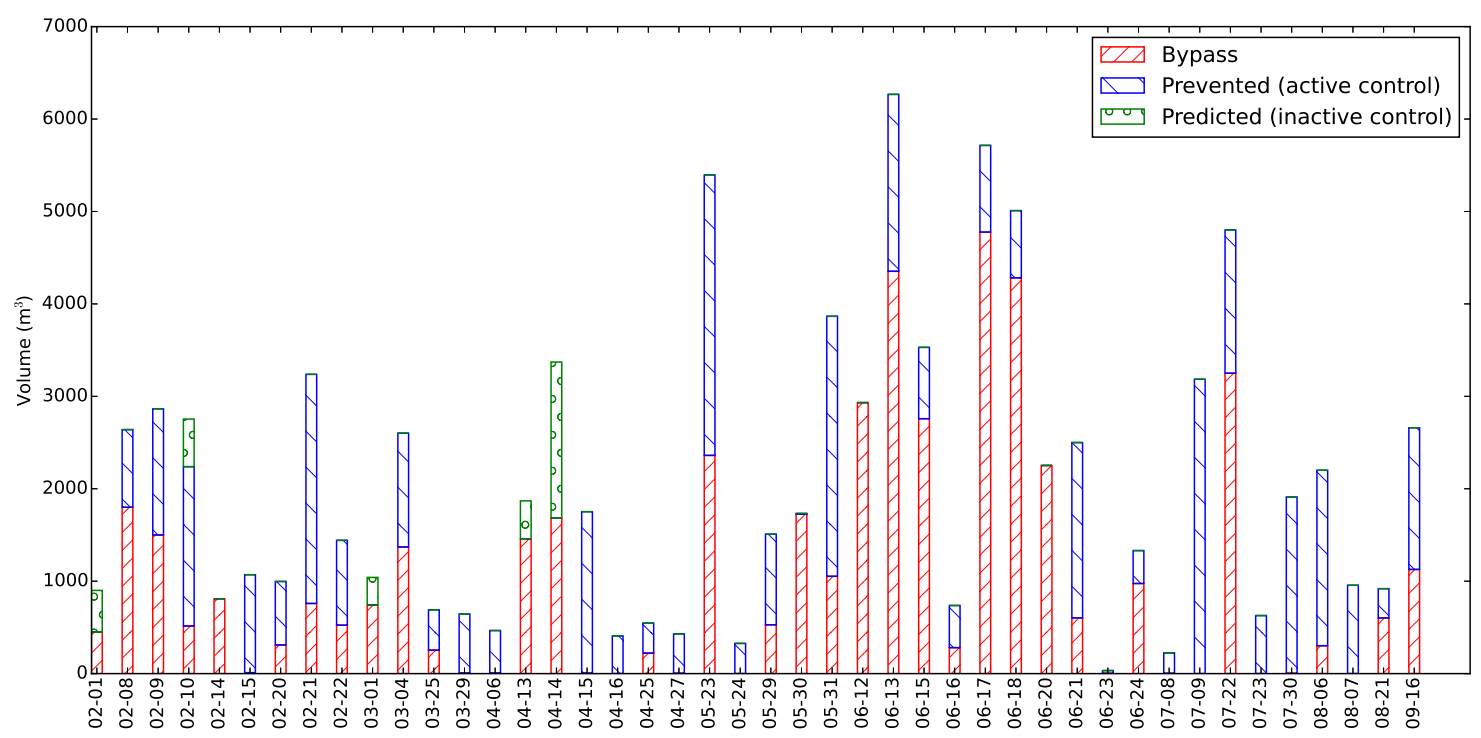

Figure 2. Performance of the predictive control at WWTP Bennekom for the period February-September 2016.

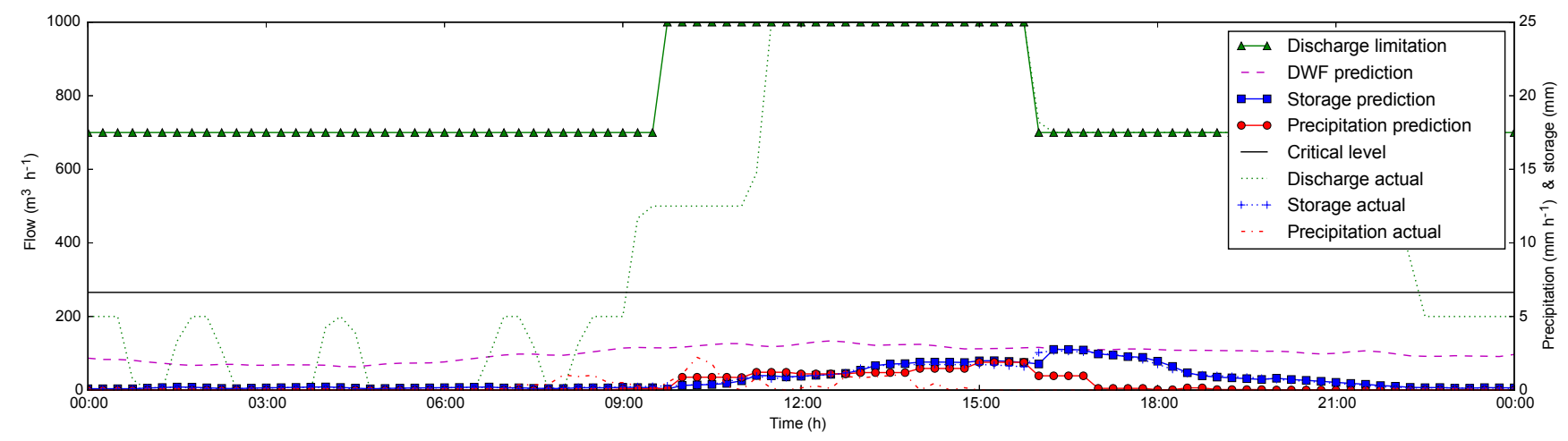

Figure 3. Example of bypass reduction with a conservative approach at WWTP Bennekom for the event of 4 March (Icke et al., 2016).

During the next 2 months (May and June) $33 \%$ of the bypass was prevented by predictive control. Especially June was a month with severe thunderstorms. The precipitation during this (early) summer period can be characterised as difficult to predict and with large amounts within short time periods. The effects of subsequent rainfall events were large. Discharge limitation of the predictive control can only occur below critical levels and without significant rainfall in the near future. Finally, during the last 3 months (JulySeptember) $70 \%$ of the bypass was prevented by predictive control.

\subsection{Performance: single rainfall events}

In this pilot project, a conservative approach is used in which the predictive control is limited after the rainfall event. In Fig. 3 bypass reduction after a rainfall event of 4 March is illustrated. The efficiency of the predictive control for this single event accounts for $47 \%$. This is entirely due to the chosen approach of applying discharge limitation after the rainfall event, not a subsequent rainfall event. If the progressive approach had been applied, allowing discharge limitation during the rainfall, bypass could be completely prevented for this specific event. This holds for the majority of the events in the spring period February-April (Icke et al., 2016).

The progressive approach could also be of interest for the summer period. In Fig. 4 bypass reduction after a rainfall event of 16 September is illustrated. Also for this thunderstorm, bypass could be completely prevented with the progressive approach. Although the progressive approach is riskier regarding $\mathrm{CSO}$, as mentioned before, it is worth considering from the perspective of bypass prevention. Risk reduction can be obtained by increasing the accuracy of the precipitation prediction. 


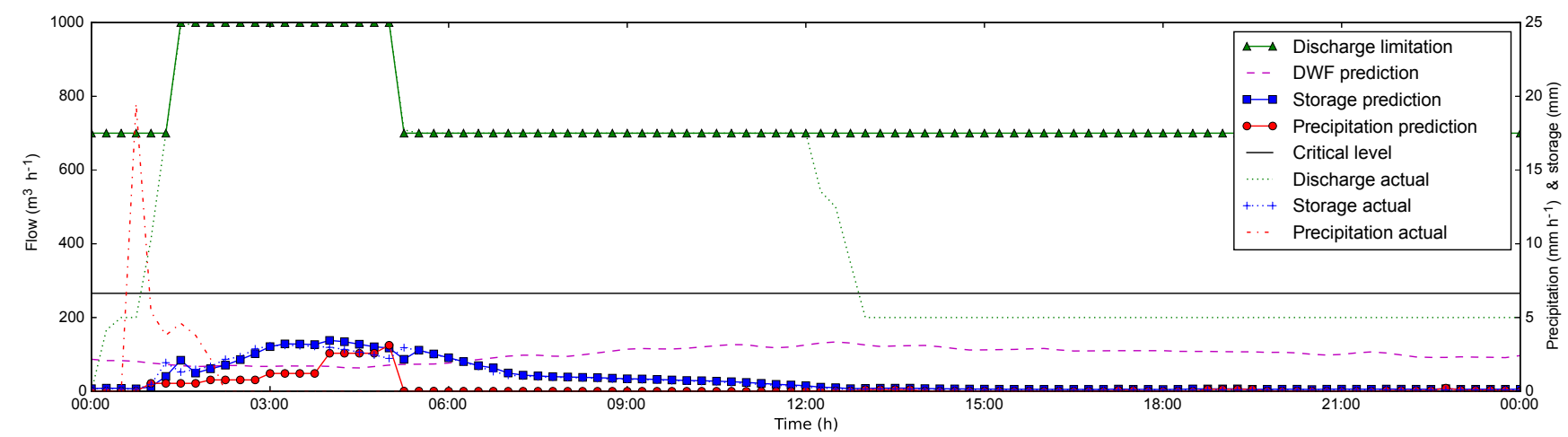

Figure 4. Example of bypass reduction with a conservative approach at WWTP Bennekom for the event of 16 September.

\subsection{Precipitation prediction}

The results show that most rainfall events are adequately predicted with respect to appearance and timing, and it is shown that this prediction can be used for control. However, further research can show whether the shape and volume of rainfall forecast might be improved by application of more advanced techniques, or a combination of techniques. Especially for the summer period, Hirlam Aladin Regional on Mesoscale Operational NWP in Euromed (HARMONIE) precipitation prediction performs better than HIRLAM (Hooijman, 2014). In addition, HARMONIE has raster cell sizes of 2.5 by $2.5 \mathrm{~km}$ (KNMI, 2010), which results in a more distinctive selection of cells for each catchment. Nowcasting extrapolates the initial condition, determined by detailed observed data, to a forecast with a horizon between 0 and $6 \mathrm{~h}$. It offers more accurate information for the very short term, but it loses its value for the long term (Golding, 1998). Although the forecast horizon of nowcasting is too short in comparison to travelling times in the sewerage, it might be meaningful to combine it with HARMONIE to use the best of both worlds. NWP unpredicted events could be covered with nowcasting. Also, the usage of the spread of ensemble forecasts accounting for uncertainty is considered. Discharge limitation could be disabled in case of unpredictable weather.

\section{Conclusions}

Flow intake based on predictive control using DWF and rainfall predictions offers reduced peak discharges on the WWTPs. This results in a better performance of the WWTP and particularly the utilisation of the post-treatment phase, which improves the surface water quality. For the analysed period (February-September 2016) results at WWTP Bennekom show that about $50 \%$ of bypass volume of the posttreatment phase can be prevented with operational predictive control. Analysis of single rainfall events showed that the approach, in which the discharge is limited after the rainfall event, is still conservative. The prevented amount can be even further increased by allowing limited discharge during significant rainfall.

Data availability. The research data of this pilot project can be accessed and all data sets are available as time series in text files (comma separated values) in the Supplement. Further explanation can be obtained by contacting the corresponding author.

\section{The Supplement related to this article is available online at https://doi.org/10.5194/dwes-10-69-2017-supplement.}

Competing interests. The authors declare that they have no conflict of interest.

Special issue statement. This article is part of the special issue "Computing and Control for the Water Industry, CCWI 2016". It is a result of the 14th International CCWI Conference, Amsterdam, the Netherlands, 7-9 November 2016.

Acknowledgements. This pilot project was carried out in cooperation with Dutch water authority Vallei and Veluwe (WSVV) and engineering corporation Royal HaskoningDHV (RHDHV). The authors would like to thank Ferry van de Peppel and Ronnie van Brummelen (WSVV) for their extensive contribution with local process automation and embedding in the daily process operation. Thanks go also to Klaas-Jan van Heeringen (Deltares) for his detailed review.

Edited by: Edo Abraham

Reviewed by: Klaas-Jan van Heeringen and one anonymous referee 


\section{References}

Bakker, M., Vreeburg, J. H. G., van Schagen, K. M., and Rietveld, L. C.: A fully adaptive forecasting model for short-term drinking water demand, Environ. Modell. Softw., 48, 141-151, 2013a.

Bakker, M., Vreeburg, J. H. G., Palmen, L. J., Sperber, V., Bakker, G., and Rietveld, L. C.: Better water quality and higher energy efficiency by using model predictive flow control at water supply systems, J. Water Supply Res. T., 62, 1-13, $2013 \mathrm{~b}$.

de Koning, M., van Schagen, K. M., Agarwalla, B., Trolio R., and Domuard, M. (Eds.): Predictive control in wastewater treatment, OZ Water'13 Conference, Perth, Australia, 2013.

Golding, B. W.: Nimrod: A system for generating automated very short range forecasts, Meteorol. Appl., 5, 1-16, 1998.

Hooijman, N.: Vergelijkende verificatie van neerslagverwachtingen van de modellen HARMONIE, HIRLAM en ECMWF (Comparative verification of precipitation forecasts from the models HARMONIE, HIRLAM and ECMWF), Tech. rep., KNMI Internal Report, IR-2014-09, 2014.

Icke, O., Huising, C., van Dijk, E. J. H., and Henckens, G. (Eds.): Pump regime optimisation by dry-weather forecasts, Proceeding of the 8th International Conference on Sewer Processes and Networks, 2016.
KNMI: Voortzetting weermodel HIRLAM (Continuation weather model HIRLAM), https://knmi.nl/over-het-knmi/nieuws/ voortzetting-weermodel-hirlam, (last access: 5 May 2016), 2010.

RIONED: Functioneel ontwerp: inzameling en transport van afvalwater en (verontreinigd) hemelwater (Functional Design: collection and transport of wastewater and (contaminated) rainwater). Leidraad Riolering (Guideline Drainage). Module B2100, http://www.riool.net/ (last access: 5 May 2016), 2008.

van der Kolk, J. H.: Aquasuite ${ }^{\circledR}$ for intelligent water solutions. Smart Water: Intelligent solutions for the entire water chain, http://aquasuite.net/, last access: 5 May 2016.

van Dijk, E. J. H.: Toepassing neerslagvoorspelling in besturing RWZI's "Case Woudenberg" (Application precipitation prediction in control WWTPs "Case Woudenberg"), Tech. rep., Royal HaskoningDHV Consultancy Report, WT-CM2021594, 2013. 